\title{
ESTRUTURA DA DEFORMAÇÃO E DA FRATURA DE CORPOS DE PROVA DE TRAÇÃO DE UM FERRO DE PUREZA ULTRAELEVADA*
}

Jadson Barbosa ${ }^{1}$

Pedro Dolabella Portella ${ }^{2}$

\section{Resumo}

Corpos de prova de ferro com diferentes níveis de pureza - um de pureza ultraelevada, dois de pureza elevada e um puro comercial - foram testados mecanicamente com diferentes taxas de deformação no âmbito de um antigo projeto. O objetivo era obter a resistência à tração de cada material e verificar a influência das impurezas e da taxa de deformação nas propriedades mecânicas do ferro de pureza ultraelevada. Para melhor compreender os resultados desses ensaios de tração, uma caracterização microscópica detalhada dessas amostras é realizada através deste trabalho. Para tal, foram analisadas as superfícies lateral e de fratura dos corpos de prova de tração no estereomicroscópio e no Microscópio Eletrônico de Varredura (MEV). O dano foi analisado em seções longitudinais ao longo do eixo de tração utilizando o microscópio óptico; a estrutura dos grãos deformados foi investigada por meio da técnica de microscopia EBSD (Difração de elétrons retroespalhados). Microestrutura, padrão de deformação, orientação dos grãos e as características das superfícies lateral e de fratura são então comparadas quanto ao processo de fabricação, nível de pureza e taxa de deformação.

Palavras-chave: Metalurgia física; Deformação plástica; EBSD; Ferro de pureza ultraelevada.

\section{DEFORMATION AND FRACTURE STRUCURE OF TENSILE SPECIMENS OF AN ULTRA-HIGH-PURITY IRON}

\section{Abstract}

Specimens of iron with different levels of purity - an ultra-high-purity, two of high-purity and a commercially pure variety - were mechanically tested with different strain rates in the frame of a former project. The objective was to determine the tensile strength of each material and analyze the influence of impurities and strain rate on the mechanical properties of the ultra-high-purity iron. To better understand the results of these tensile tests, a detailed microscopic characterization of these materials is carried out through this work. For this purpose, the lateral and fracture surfaces of the tensile specimens were examined by using a stereo microscope and a Scanning Electron Microscope (SEM). The damage was analyzed in longitudinal sections along the tensile axis by using an optical microscope; the structure of the deformed grains was investigated by using EBSD (Electron backscatter diffraction). Microstructure, deformation pattern, grains orientation and the characteristics of the lateral and fracture surfaces are then compared with respect to the manufacturing process, purity level and strain rate.

Keywords: Physical metallurgy; Plastic deformation; Ultra-high-purity iron; EBSD.

1 Graduando em Engenharia de Materiais, Departamento de Engenharia Mecânica, Universidade Federal de Santa Catarina - UFSC, Florianópolis, Santa Catarina, Brasil.

2 Doutor em Ciência e Engenharia de Materiais, Doutor Engenheiro, Chefe de departamento, Departamento 5.0 - Engenharia de Materiais, Instituto Federal para Pesquisa e Teste de Materiais - BAM, Berlim, Alemanha. 


\section{INTRODUÇÃO}

Os mecanismos que provocam a deformação elástica e plástica e a fratura dos materiais já são bem conhecidos e descritos através da metalurgia física. Contudo, diferentes mecanismos podem agir quando se altera, por exemplo, a pureza ou a taxa de deformação utilizada no ensaio. Diferentes elementos também podem ter diferentes influências nas propriedades dos materiais. Uma das utilidades do ferro de pureza ultraelevada, que é objeto recente de pesquisa, é servir de base para avaliar as propriedades intrínsecas do ferro [1], bem como analisar a influência inerente de cada impureza nessas propriedades, sendo extremamente importante no desenvolvimento de materiais ferrosos, Abiko apud NIST Technical Note 1879 [2].

Há algum tempo, através de um Round Robin internacional, foi avaliada a influência de impurezas e de diferentes taxas de deformação nas propriedades mecânicas do ferro de ultraelevada pureza em relação ao ferro de elevada pureza e ao ferro puro comercial. Os corpos de prova de tração foram produzidos pela Universidade de Tohoku, no Japão [2].

O principal objetivo deste trabalho é avaliar os efeitos das impurezas e das diferentes taxas de deformação na microestrutura dos materiais, relacionando os resultados com o processo de fabricação e com as propriedades mecânicas obtidas anteriormente, além de caracterizar os diferentes tipos de deformação e características das superfícies de fratura através de abordagens metalúrgicas.

\subsection{Discordâncias e Deformação Plástica}

Existem, na estrutura dos materiais, uma série de defeitos que geram uma descontinuidade ou desordem no cristal, como lacunas, contornos de grãos, átomos intersticiais, discordâncias, vazios, entre outros [3]. As discordâncias são um defeito inerente do material, que podem surgir sem a influência de fatores externos, ou por influência de agentes nucleantes, como partículas de impureza [4], além de aumentar sua densidade com a deformação plástica. Já os contornos de grão são muito importantes para a deformação plástica, pois atuam como barreira ao movimento de discordâncias em baixas temperaturas. Na prática, isso significa que um material com grãos pequenos terá mais barreiras à movimentação de discordâncias [5].

A deformação plástica ocorre devido ao deslizamento de átomos através dos planos e direções cristalográficas mais compactos. Para o ferro, de estrutura CFC, esses planos não são tão bem definidos, de modos que as linhas de escorregamento são onduladas e reticulares [4]. No caso de metais puros, é possível que as discordâncias formem uma estrutura de subgrão, que são células cristalinas menores no interior de um grão com pequena diferença de orientação entre si, mesmo durante o processo de deformação, até mesmo em baixas temperaturas, processo chamado de recuperação dinâmica.

\subsection{Fratura}

Ferro é um material dúctil, apresentando fratura que se forma pela nucleação e crescimento de trincas na região de estricção. Inclusões nucleiam poros, que coalescem e formam trincas na região de estricção, razão pela qual materiais mais puros (com pouca ou quase nenhuma inclusão) se deformam mais, tendo uma área de fratura menor [4]. As trincas podem se propagar por um mecanismo denominado lâminas de cavidades, que são as bandas de cisalhamento (a cerca de $40^{\circ}$ a $45^{\circ} \mathrm{com}$ 
o eixo da força de tração), locais de intensa deformação, onde surgem poros. Quando vista em grandes aumentos, há estruturas que se parecem com um conjunto de taças ordenadas na superfície, cada uma correspondendo a um poro da lâmina de cavidades, os quais foram deformados. Essas cavidades são conhecidas como dimples ou alvéolos. Também é possível que orifícios se abram no fundo dessas taças, que são conexões com poros que estão sob essa superfície [4]. O mecanismo pode ser visto na figura 1.

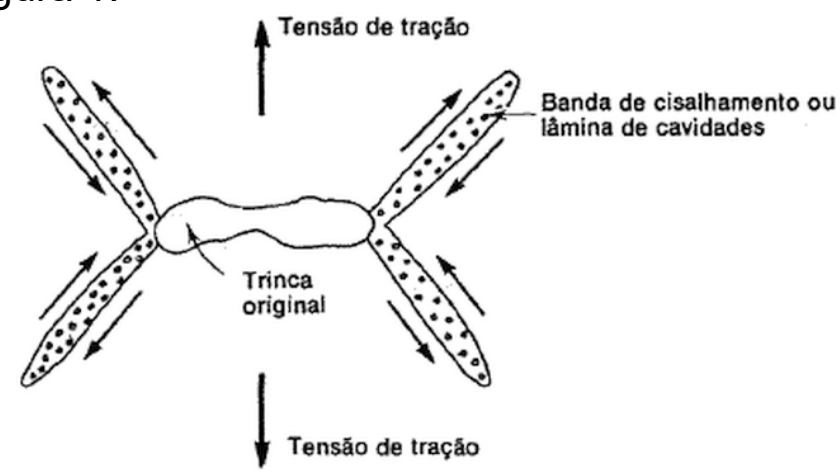

Figura 1. Mecanismo de lâminas de cavidades [4]

O número, formato e tamanho dos dimples depende do número de defeitos internos que o material possui e da ductilidade do material. No caso de materiais com alta ductilidade e poucos defeitos ocorrem dimples maiores e mais profundos com linhas de escoamento e vestígios de cisalhamento nas suas superfícies internas; caso o material contenha mais impurezas e menor ductilidade, surge um número muito grande de dimples menores [6].

\subsection{Técnica EBSD}

A análise de EBSD (Electron backscatter diffraction ou difração de elétrons retroespalhados) consiste na incidência de um feixe fino e focado de elétrons no material. Alguns deles são refratados para longe pela estrutura cristalina, atingindo uma tela de fósforo, posicionada perto do material. Os padrões de luz gerados são detectados e gravados por uma câmera digital. Esses padrões, conhecidos como padrões de Kikuchi, representam os planos da estrutura cristalina, proporcionando a identificação da estrutura cristalina do material na região onde incide o feixe de elétrons [7].

\section{MATERIAIS E MÉTODOS}

Em Sendai, no Japão, foram produzidos quatro tipos de ferro com diferentes níveis de pureza [2] (em parênteses está indicado como serão identificados no decorrer do trabalho):

- Ferro puro comercial (CP) - 99,98396\%

- Ferro de pureza elevada (HPK) - 99,9916\%

- Ferro de pureza elevada (HPS): 99,99118\%

- Ferro de pureza ultraelevada (UHP): 99,9999878\%

O conteúdo de carbono e oxigênio desses materiais pode ser verificado na tabela 1:

Tabela 1. Conteúdo de carbono e oxigênio (em ppm) [2]

\begin{tabular}{ccccc}
\hline Elemento & CP & HPK & HPS & UHP \\
\hline $\mathrm{C}$ & 14.6 & 1.6 & 0.3 & 0.5 \\
\hline $\mathrm{O}$ & 1.8 & 4 & 1.5 & $<0.1$ \\
\hline
\end{tabular}


Os materiais CP e HPK foram fundidos em cadinho de cerâmica em atmosfera de Argônio (26,9 MPa) e os materiais HPS e UHP foram fundidos em cadinho de cobre resfriado com água em vácuo ultraelevado $\left(10^{-7} \mathrm{~Pa}\right)$. Esses lingotes passaram então por forjamento, laminação das ranhuras, estampagem, usinagem, tratamento térmico para recristalização em vácuo ultraelevado e polimento químico, obtendo-se como produto final um espécime de tração. Esses corpos de prova de tração foram então testados com taxas de deformação de $10^{-3} \mathrm{~s}^{-1}, 10^{-4} \mathrm{~s}^{-1}$ e $10^{-5} \mathrm{~s}^{-1}$ [2] (assim, CP3 indica espécime tracionado com uma taxa de $10^{-3} \mathrm{~s}^{-1}$, CP4 com uma taxa de $10^{-4} \mathrm{~s}^{-1}$ e assim por diante). Na figura 2 pode-se ver o resultado para o limite de escoamento das amostras que foram avaliadas pelo BAM (Instituto Federal de Pesquisa e Teste de Materiais):

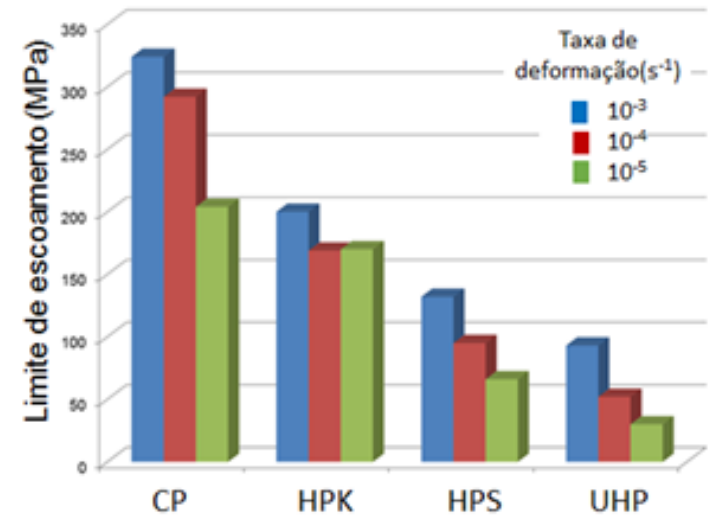

Figura 2. Limite de escoamento das amostras [2]

Partindo-se da grande diferença nas propriedades mecânicas apesar de pouca diferença no grau de pureza, foram investigadas as superfícies lateral e de fratura, o dano e a deformação ao longo dos corpos de prova e a estrutura dos grãos utilizandose o estereomicroscópio, o microscópio óptico e o microscópio eletrônico de varredura. A preparação metalográfica foi feita lixando-se longitudinalmente até o eixo de tração, na metade dos corpos de prova, possibilitando a análise da deformação e estrutura dos grãos.

\section{RESULTADOS E DISCUSSÃO}

Serão apresentados os principais resultados na comparação entre as amostras de ferro, da superfície lateral, de fratura, dano ao longo do corpo de prova e estrutura dos grãos.

\subsection{Superfície Lateral}

A figura 3 mostra o desenho da deformação lateral nas amostras: 


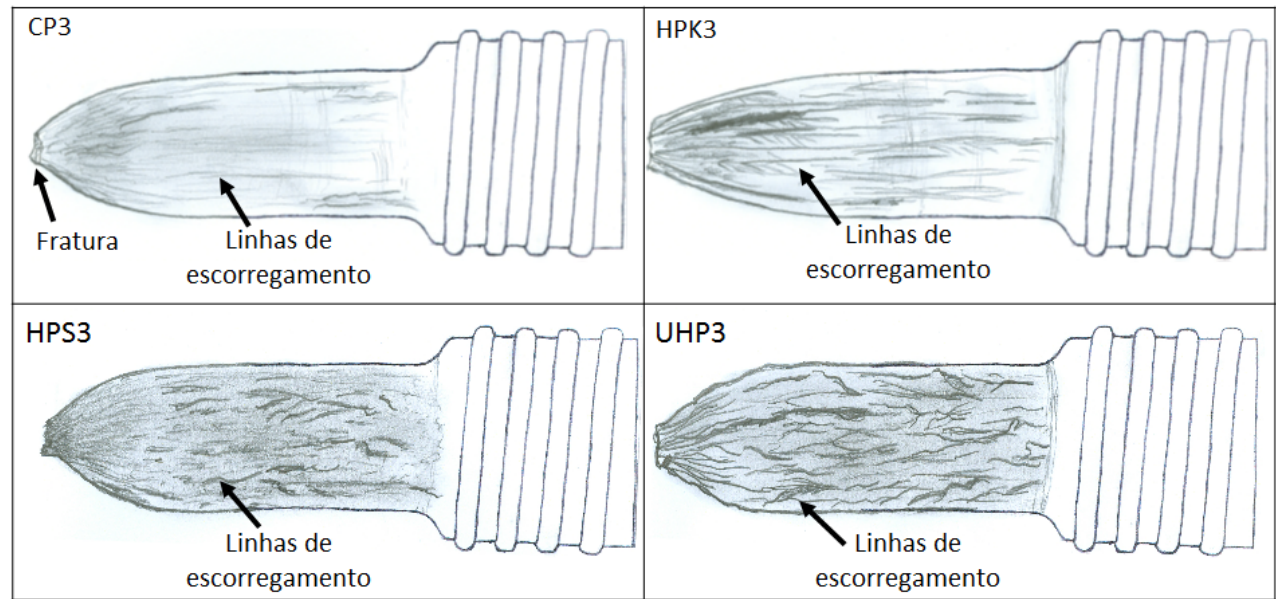

Figura 3. Deformação lateral das amostras tracionadas com a taxa de $10^{-3} \mathrm{~s}^{-1}$

Como são apenas desenhos, sem escala, não se deve comparar o comprimento do trecho deformado. Nessas figuras pode-se observar as linhas de escorregamento, que começam a partir da região de curvatura da rosca e se estendem até a fratura. Por ser um material CCC e os planos de deslizamento não serem tão compactos e definidos, originam-se essas linhas onduladas e com certo caráter reticular, como se constata em HPK3.

Além disso, nota-se como o número dessas linhas e consequentemente da deformação aumenta com a pureza do material (CP<HPK<HPS $<\mathrm{UHP})$. Quanto mais puro o material é, menos obstáculos existirão para a movimentação desses sistemas de escorregamento, originando uma deformação maior. Nos materiais HPS3 e UHP3 observa-se uma grande quantidade de linhas de deslizamento próximas à rosca, 0 que pode ser sinônimo de uma deformação mais homogênea. No UHP3 também é possível ver a existência de uma superfície não tão linear como nos outros três materiais.

Abaixo, na figura 4, uma comparação da deformação em função da taxa de deformação para um mesmo material. Podemos ver que diminuem as linhas de deformação à medida que diminui a taxa de deformação.

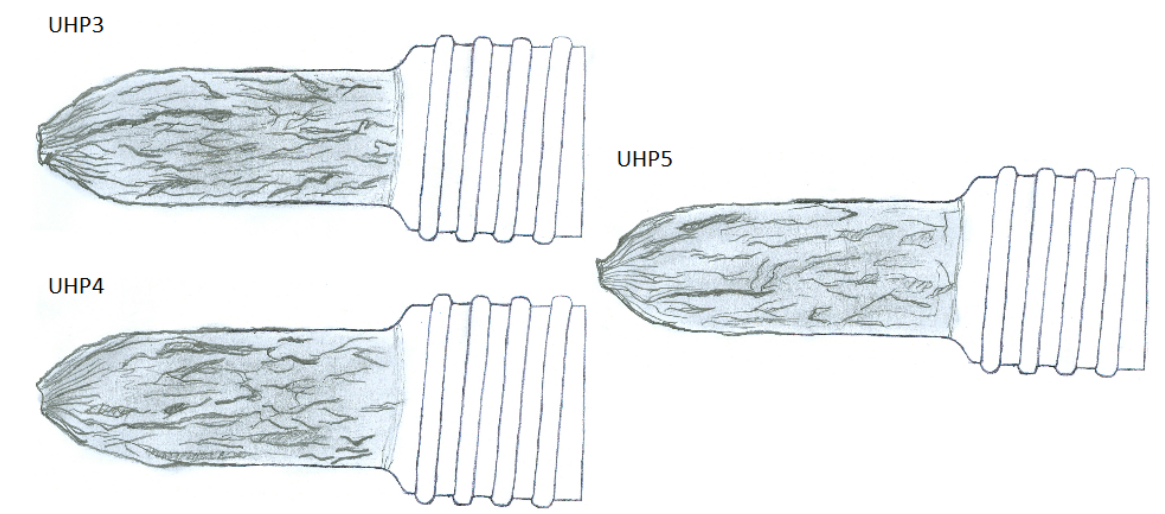

Figura 4. Comparação da deformação em função da taxa de deformação para o UHP

\subsection{Superfície de Fratura}

Todos os materiais analisados apresentaram uma fratura dúctil, com alveólos de diferentes tamanhos, conforme figura 5 . 


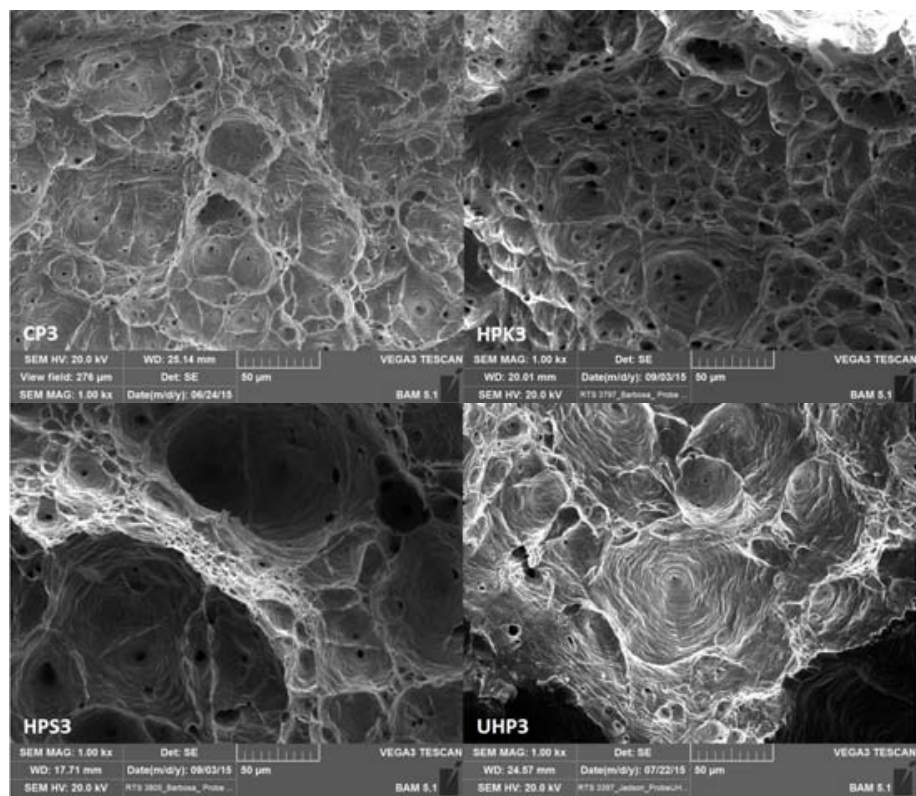

Figura 5. Superfície de fratura do CP3, HPK3, HPS3 e UHP3 com aumento de 1000x

Como visto na figura 5, os materiais HPS3 e UHP3 tem maiores dimples, o que ocorre devido ao seu baixo conteúdo de impurezas ou defeitos na estrutura cristalina, que permitem que os dimples cresçam mais. O HPK3 (que foi fundido em atmosfera de argônio e que possui alto teor de oxigênio) apresenta muitos poros, enquanto o UHP, o mais puro, não tem quase nenhum. Isso ocorre porque o UHP tem menos defeitos que podem barrar a deformação.

Enquanto o HPK3 (aquele que tinha um alto teor de oxigênio e foi fundido em atmosfera de argônio) tem muitos poros, o UHP, o mais puro, não tem quase nenhum. Cada dimple corresponde a um poro que coalesceu devido à tensão de cisalhamento devido à nucleação de trincas durante a estricção.

Na figura 6 é feita uma comparação entre as superfícies de fratura dos dois ferros de alta pureza, o HPK3 e o HPS3.

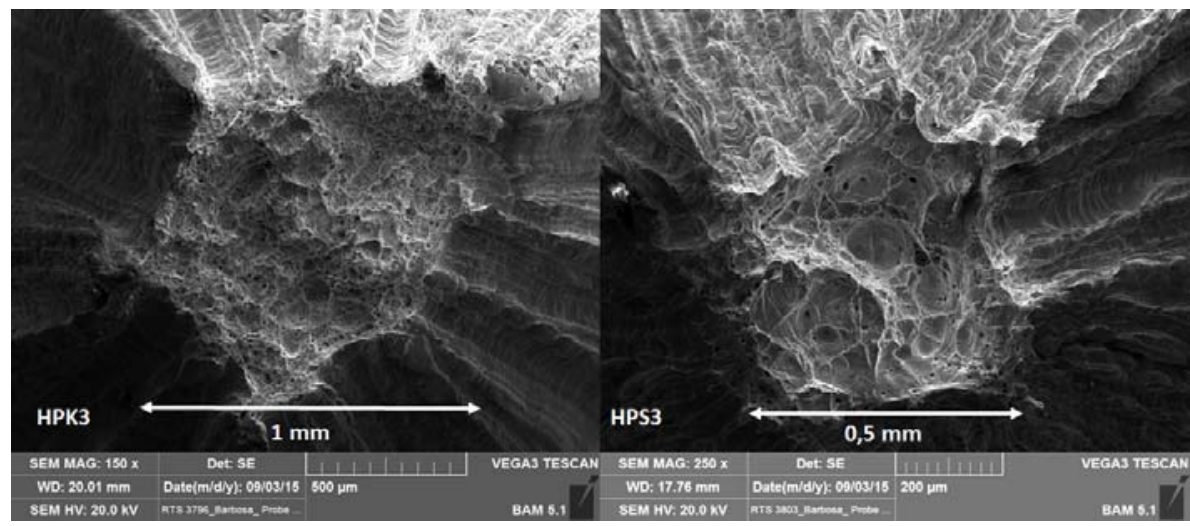

Figura 6. Superfície de fratura do HPK3 e do HPS3

Apesar de ambos se tratarem de ferros de alta pureza com composição parecida, o HPK3, fundido em atmosfera de Argônio em cadinho de cerâmica e o HPS3, fundido em cadinho de cobre resfriado com água em ultraelevado vácuo, apresentam uma superfície de fratura muito diferente. Também é relevante o fato de os dois terem um valor considerável de oxigênio, conforme Tabela 1. Possivelmente as diferentes variáveis da fabricação, como cadinho, atmosfera e condições de pressão influenciam nas diferenças microestruturais. 
Também foi verificado que não houve mudança significativa na superfície de fratura dos materiais quando a taxa de deformação foi alterada.

\subsection{Dano ao longo dos corpos de prova}

Na figura 7 está a microestrutura dos corpos de prova na região da rosca, sem deformação. É possível ver nos materiais grãos alongados devido à recristlização e grãos maiores nos materiais mais puros. Os grãos menores em HPS3 e UHP3 explicam os valores mais baixos de resistência à tração e limite de escoamento, uma vez que materiais com grãos menores (CP3) apresentam maior resistência mecânica. Além disso, pode-se observar poros no material HPK3, provavelmente devido ao teor de oxigênio.

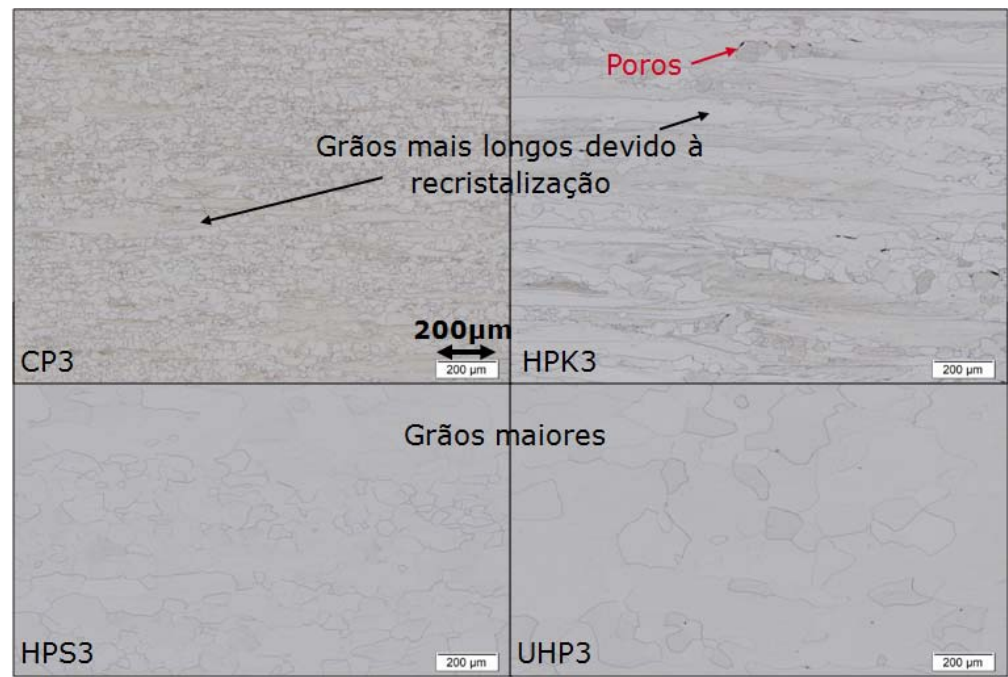

Figura 7. Microestrutura das amostras na região da rosca (sem deformação)

A figura 8 mostra o dano ao longo da amostra UHP3:

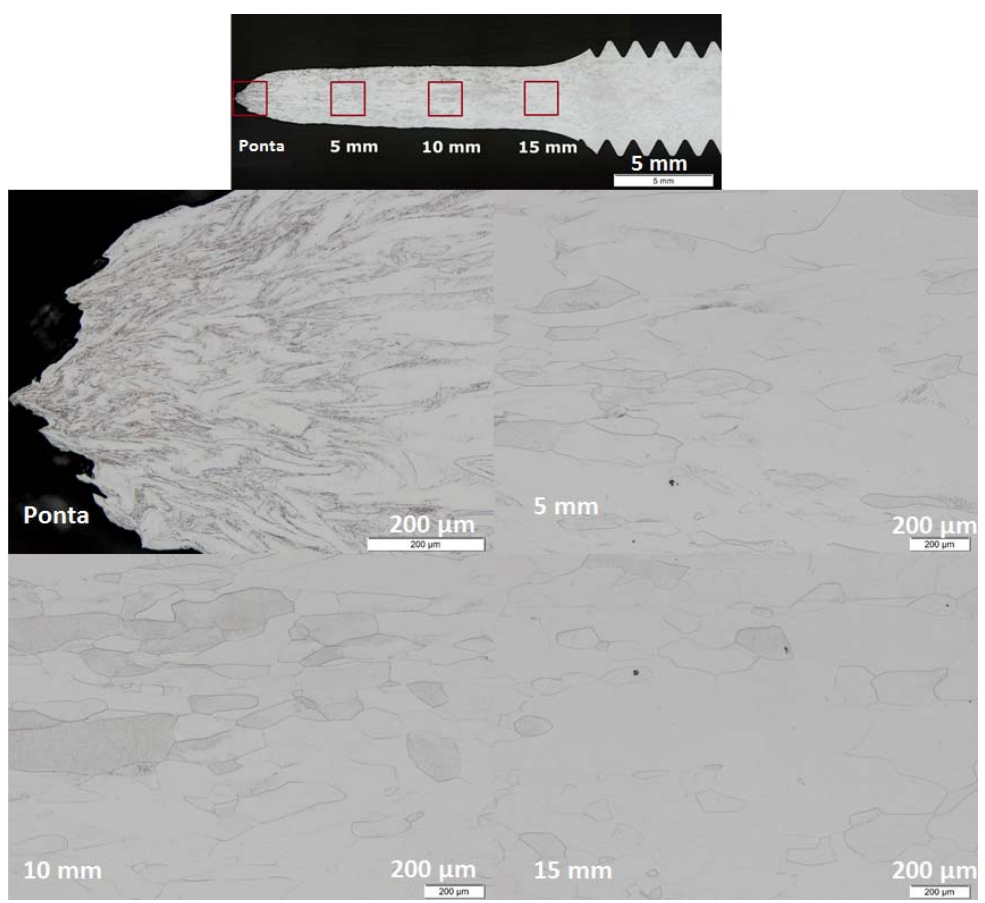

Figura 8. Deformação ao longo do corpo de prova UHP3 
Como pode ser visto na figura 8, o UHP3, tal como o HPS3 apresentam grãos mais alongados na região próxima da rosca, o que indica uma deformação mais uniforme. As micrografias também apresentaram regiões com possíveis ataques às discordâncias em regiões de intensa deformação, com acúmulo de discordâncias, principalmente próximo da fratura. No UHP3 e HPS3 foram detectados ainda grãos mais alongados perto da região da rosca, o que indica uma deformação mais homogênea.

\subsection{Estrutura dos grãos}

A textura dos grãos foi investigada por meio da técnica EBSD. A análise para a amostra UHP3 pode ser vista na figura 9. Podemos observar claramente que os grãos se deformam até $15 \mathrm{~mm}$, quando estão já muito perto da rosca. Isso indica que o material apresenta uma deformação muito homogênea, concentrando-se mais na região de fratura. $\mathrm{Na}$ imagem a $25 \mathrm{~mm}$ tem-se grãos sem nenhuma deformação ou alongamento. Principalmente na região do pico e a $5 \mathrm{~mm}$ ainda se pode ver a presença de diferentes cores dentro de um grão, ou seja, deformação da rede cristalina dentro do grão.

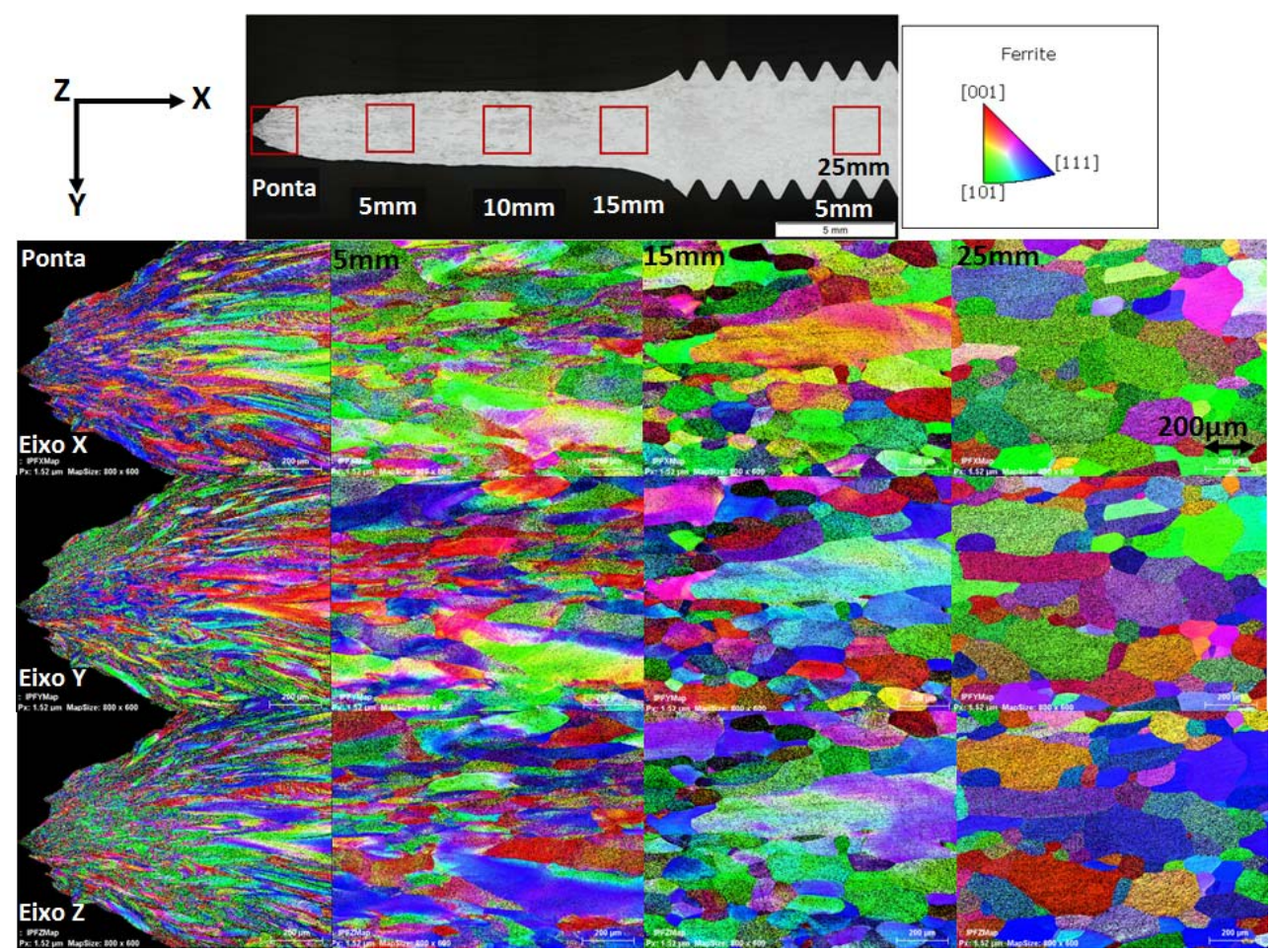

Figura 9. Estrutura dos grãos ao longo do corpo de prova UHP3

\section{CONCLUSÃO}

O ferro de pureza ultraelevada e o ferro de pureza elevada HPS, com uma rede cristalina sem muitas imperfeições, facilitam o movimento de planos cristalográficos e discordâncias, ou seja, possui baixa resistência mecânica e são deformados mais homogeneamente. Taxas de deformação mais elevadas revelaram uma deformação mais acentuada do material, consistente com os valores de resistência mecânica obtidos.

Contrariamente, o ferro comercialmente puro $\mathrm{CP}$, com mais barreiras ao movimento de discordâncias, apresentou, junto com o ferro de elevada pureza HPK, maior 
resistência à tração e limite de escoamento, mas alongamento mais baixo, bem como uma deformação mais reticular e não tão homogênea ao longo do espécime de tração. O ferro de pureza elevada HPK provavelmente influenciado pelo processo de fabricação. Ele não foi fundido em vácuo, retendo possivelmente bolhas de ar na microestrutura, gerando porosidade e afetando as propriedades mecânicas.

Todas as superfícies de fratura apresentaram caráter dúctil, com fratura transgranular e diferentes tamanhos de dimples. Dimples maiores foram observados nos materiais mais puros; dimples menores foram encontrados em materiais com mais impurezas. Dimples maiores ocorrem devido à menor quantidade de barreiras ao seu movimento, de modo que eles podem ter um coalescimento maior que em materiais com uma rede cristalina com mais defeitos.

O tamanho de grão também depende dos tratamentos térmicos e impurezas. Mais impureza significa mais região possível para a nucleação de grãos. É o possível motivo para que o ferro de pureza ultraelevada tenha uma microestrutura com grãos maiores em relação principalmente ao ferro puro comercial. Em regiões com deformação mais concentrada e na ausência de impurezas para ataque químico preferencial, é possível também que tenha ocorrido o ataque às discordâncias.

Através do EBSD foi possível localizar principalmente em regiões com intensa deformação, uma possível rotação da rede cristalina devido ao ensaio de tração, gerando grãos deformados (diferentes cores dentro de um grão).

\section{Agradecimentos}

Jadson Barbosa agradece ao apoio do programa Ciência sem Fronteiras, chamada $157 / 2013$, através da CAPES, que deu apoio financeiro para as atividades no exterior, bem como ao BAM - Instituto Federal de Pesquisa e Teste de Materiais, pela estrutura e suporte oferecidos.

\section{REFERÊNCIAS}

1 Waseda, Y., Isshiki, M. Purification Processes and Characterization of Ultra High Purity Metals: Application of Basic Science to Metallurgical Processing. Berlin: Springer; 2002.

2 Lucon, E., Abiko, K., Lambrecht, M., Rehmer, B. Tensile Properties of Commercially Pure, High-Purity and Ultra-High-Purity Iron: Results of an International Round-Robin. NIST Technical Note 1879, USA; 2015.

3 Smallman, R.E., Ngan, A.W.H. Mechanical Physical Metallurgy and Advanced Materials. 7 ed. Burlington: Elsevier; 2007.

4 Reed-Hill, R. E.Physical Metallurgy Principles. 2 ed. USA: Van Nostrand Company; 1973.

5 Meyers, K. C., Chawla, K. K. Mechanical Metallurgy: Principles and Applications. New Jersey: Prentice-Hall; 1984.

6 Verein Deutscher Eisenhüttenleute. Erscheinungsformen von Rissen und Brüchen metallischer Werkstoffe - The Appearance of Cracks and Fractures in Metallic Materials. Düsseldorf: Stahleisen; 2012.

7 EDAX. Electron Backscatter Diffraction. 2 ed. Chichester: John Wiley and Sons, 2015. 